\title{
Impact of menstrual blood loss and diet on iron deficiency among women in the UK
}

\author{
Linda J. Harvey ${ }^{*}$, Charlotte N. Armah ${ }^{1}$, Jack R. Dainty ${ }^{1}$, Robert J. Foxall ${ }^{1}$, D. John Lewis ${ }^{2}$, Nicola J. Langford ${ }^{2}$ \\ and Susan J. Fairweather-Tait ${ }^{1}$ \\ ${ }^{1}$ Institute of Food Research, Norwich Research Park, Colney, Norwich NR4 7UA, UK \\ ${ }^{2}$ Central Science Laboratory, Sand Hutton, York, YO4 1LZ, UK
}

(Received 20 May 2004 - Revised 3 March 2005 - Accepted 31 March 2005)

\begin{abstract}
Women of childbearing age are at risk of Fe deficiency if insufficient dietary Fe is available to replace menstrual and other Fe losses. Haem Fe represents $10-15 \%$ of dietary Fe intake in meat-rich diets but may contribute $40 \%$ of the total absorbed Fe. The aim of the present study was to determine the relative effects of type of diet and menstrual Fe loss on Fe status in women. Ninety healthy premenopausal women were recruited according to their habitual diet: red meat, poultry/fish or lacto-ovo-vegetarian. Intake of Fe was determined by analysing $7 \mathrm{~d}$ duplicate diets, and menstrual Fe loss was measured using the alkaline haematin method. A substantial proportion of women (60\% red meat, $40 \%$ lacto-ovo-vegetarian, $20 \%$ poultry/fish) had low Fe stores (serum ferritin $<10 \mu \mathrm{g} / \mathrm{l})$, but the median serum ferritin concentration was significantly lower in the red meat group $(6 \cdot 8 \mu \mathrm{g} / \mathrm{l}$ (interquartile range $3 \cdot 3$, 16.25)) than in the poultry/fish group $(17.5 \mu \mathrm{g} / \mathrm{l}$ (interquartile range $11.3,22.4)(P<0.01)$. The mean and standard deviation of dietary Fe intake were significantly different between the groups $(P=0.025)$; the red meat group had a significantly lower intake (10.9 (SD 4.3$) \mathrm{mg} / \mathrm{d})$ than the lacto-ovo-vegetarians (14.5 (SD 5.5) mg/d), whereas that of the poultry/fish group $(12.8(\mathrm{SD} 5 \cdot 1) \mathrm{mg} / \mathrm{d})$ was not significantly different from the other groups. There was no relationship between total Fe intake and Fe status, but menstrual Fe loss $(P=0 \cdot 001)$ and dietary group $(P=0 \cdot 040)$ were significant predictors of Fe status: poultry/fish diets were associated with higher Fe stores than lacto-ovo-vegetarian diets. Identifying individuals with high menstrual losses should be a key component of strategies to prevent Fe deficiency.
\end{abstract}

Iron deficiency: Menstrual loss: Fe status: Women: Vegetarian: Meat

The risk of Fe deficiency in women of childbearing age is considerable because of the additional Fe demands of menstruation and pregnancy. The reported percentage of menstruating women with a low Fe store, estimated from serum ferritin concentration, varies between countries (Hallberg, 1995) owing to differences in Fe supply (dietary patterns and use of supplements) and Fe losses (contraceptive practice, blood donation, parity). Furthermore, there are well-recognised methodological problems associated with the use of serum ferritin as an index of Fe status, including elevated values resulting from minor infection that are not related to the level of Fe stores (Hulthen et al. 1998) and imprecision of measurement related to day-to-day variability (Borel et al. 1991; Cooper \& Zlotkin, 1996).

The primary homeostatic mechanism for maintaining $\mathrm{Fe}$ balance is the absorptive efficiency of the small intestine (Andrews, 1999). However, only a proportion of dietary $\mathrm{Fe}$ is available for absorption, depending on the composition of the diet, so when physiological requirements outstrip $\mathrm{Fe}$ supply, Fe-deficiency anaemia will develop once the body stores have been exhausted. Haem $\mathrm{Fe}$, which constitutes $30-70 \%$ of all $\mathrm{Fe}$ found in meat, is more readily absorbable than non-haem Fe found in both meat and plant foods. Although haem Fe represents only $10-15 \%$ of dietary $\mathrm{Fe}$ intake in meat-rich diets, it may contribute $40 \%$ or more of the total absorbed Fe in omnivores (Bjorn-Rasmussen et al. 1974). There are few published data on the actual haem Fe content of different flesh foods, but it is generally accepted that the haem Fe content of fish and poultry is less than that of red meat. There are also few data on menstrual blood loss in women in the UK (Higham \& Shaw, 1999; Wyatt et al. 2001), and the current dietary reference value for Fe intake (Department of Health, 1991) in women of childbearing age is based on measurements of menstrual blood loss obtained from a Swedish study several decades ago (Hallberg et al. 1966), before the use of oral contraceptives was commonplace.

The bioavailability of Fe from a Western-type diet, containing significant quantities of meat and vitamin $\mathrm{C}$ (enhancers of $\mathrm{Fe}$ absorption), is generally assumed to be relatively high, in the region of $15 \%$ (Food and Agriculture Organization/World Health Organization, 1988). Dietary patterns are changing in response to health issues. In Europe, the BSE crisis precipitated changes in the type and quantity of meat consumed (Morabia et al. 1999), and the recent popularity of different weight-reducing regimens, such as the Atkins diet, has introduced yet more variations in meat consumption (Anderson et al. 2000). In the UK, vegetarianism is increasingly popular (Vegetarian Society, 2000), and in the latest National Diet and Nutrition Survey, $5 \%$ of adults described themselves as vegetarian (Henderson et al. 2002). In a recent poll in the UK (Vegetarian Society, 2001), $4 \%$ of people reported 
that they consumed vegetarian diets and $33 \%$ ate meat only occasionally; it is estimated that 7 million people in the UK $(12 \%$ of the population) are either vegetarian or avoid red meat.

The relative importance of menstrual blood loss and dietary $\mathrm{Fe}$ intake in influencing the risk of Fe deficiency in women consuming lacto-ovo-vegetarian and meat-containing diets is not well defined, but there are reports that vegetarianism is associated with menstrual disturbances (Barr, 1999) and a lower Fe status than in omnivores (Helman \& Darnton-Hill, 1987; Reddy \& Sanders, 1990; Alexander et al. 1994; Nelson et al. 1994). Dietary surveys of vegetarians have generally found total $\mathrm{Fe}$ intakes to be similar (McEndree et al. 1983; Worthington-Roberts et al. 1988; Alexander et al. 1994; Ball \& Bartlett, 1999) or higher (Reddy \& Sanders, 1990) than those in omnivores. However, whether women consuming Western-style vegetarian diets are at a higher risk of $\mathrm{Fe}$ deficiency than their omnivorous counterparts requires clarification (Hunt, 2003).

The relationship between dietary Fe absorption and Fe stores is well characterised, with higher absorption in Fe-deficient and lower absorption in Fe-replete individuals (Bothwell et al. 1979). There are, however, only limited data describing variables affecting the $\mathrm{Fe}$ status of women of childbearing age (Heath et al. 2001; Whitfield et al. 2003). No study has examined the combined effect of menstrual blood loss and diet to elucidate the relative importance of these factors for $\mathrm{Fe}$ status in menstruating women. The current study describes data on menstrual blood loss and type of habitual diet, and their impact on the risk of Fe deficiency in women of childbearing age consuming omnivorous or vegetarian diets in the UK.

\section{Subjects and methods}

\section{Subjects}

Ninety healthy, premenopausal women aged 18-45 years were recruited through local advertisements to take part in the study. Volunteers were not accepted for the study if they had donated blood during the previous 6 months because of the reported effect of blood donation on Fe stores (Borch-Iohnsen et al. 1990). A $10 \mathrm{ml}$ screening blood sample was taken to exclude subjects whose biochemical and haematological indices fell outside the normal range.

Clinical screening (normal ranges in brackets) included: leucocyte count $\left(4.0-11.0 \times 10^{9} / 1\right)$, neutrophils $\left(2.5-7.5 \times 10^{9} / 1\right)$, lymphocytes $\left(1.1-3.5 \times 10^{9} / 1\right)$, erythrocytes $\left(3.9-5.6 \times 10^{12} / 1\right)$, Hb $(11.5-16.4 \mathrm{~g} / \mathrm{dl})$, haematocrit $(0.37-0.47)$, mean corpuscular volume $(80-100 \mathrm{fl})$, mean corpuscular $\mathrm{Hb}(27-32 \mathrm{pg})$, platelet concentration $\left(150-400 \times 10^{9} / \mathrm{l}\right), \quad \mathrm{Na} \quad(134-145 \mathrm{mmol} / \mathrm{l}), \quad \mathrm{K}$ $(3 \cdot 6-5.0 \mathrm{mmol} / \mathrm{l}), \mathrm{HCO}_{3}^{-}(22-30 \mathrm{mmol} / \mathrm{l})$, urea $(1 \cdot 7-7 \cdot 1 \mathrm{mmol} /$ $1)$ creatinine $(55-125 \mu \mathrm{mol} / \mathrm{l})$, total bilirubin $(0-22 \mu \mathrm{mol} / \mathrm{l})$, total protein $(63-82 \mathrm{~g} / \mathrm{l})$, albumin $(35-50 \mathrm{~g} / \mathrm{l})$, globulin $(21-35 \mathrm{~g} / \mathrm{l})$, alanine aminotransferase $(0-50 \mathrm{U} / \mathrm{l}), \gamma$-glutamyl transferase $(0-60 \mathrm{U} / \mathrm{l})$, total cholesterol $(3.6-6.5 \mathrm{mmol} / \mathrm{l})$ and glucose $(3 \cdot 5-7 \cdot 0 \mathrm{mmol} / \mathrm{l})$.

Five women were excluded from the study as a result of clinical screening: three in the poultry/fish group (raised leucocyte count, mean corpuscular volume and mean corpuscular $\mathrm{Hb}$, and a low platelet count) and two in the vegetarian group (raised mean corpuscular volume, mean corpuscular $\mathrm{Hb}$, leucocyte count, neutrophils and lymphocytes). No women were excluded owing to a low $\mathrm{Hb}$ concentration. Other exclusion criteria included chronic illness, taking medication (except oral contraceptives) or nutritional supplements, smoking, pregnancy within the previous 12 months, and lactation.

All volunteers completed a food-frequency questionnaire in order to allocate subjects to one of three dietary groups. Each group contained thirty volunteers, and the groups were defined as follows:

- Red meat: eaten at least five times per week $(5 \times 90 \mathrm{~g}$ cooked weight). Subjects were also allowed to eat poultry and fish.

- Poultry/fish: eaten at least five times per week $(5 \times 90 \mathrm{~g}$ cooked weight). Subjects were also allowed to consume a maximum of $90 \mathrm{~g}$ pork or ham once per week, but no other red meat.

- Lacto-ovo-vegetarian: no meat or fish eaten for at least 1 year.

Several women were ineligible to take part in the study because of their habitual consumption of either insufficient or excess red meat to enter either the red meat or poultry/fish group, respectively. The subjects in this study were actually taking part in a much larger study involving $\mathrm{Fe}, \mathrm{Zn}$ and $\mathrm{Cu}$ absorption measurements (data not shown). The sample size for the study was based on the Fe absorption data; with $80 \%$ power and assuming a standard deviation of $7 \%$ in $\mathrm{Fe}$ absorption, a total of ninety subjects (thirty per dietary group) were required to detect a $5 \%$ difference in Fe absorption.

The study was approved by the Norwich District Ethics Committee and all subjects gave written informed consent.

\section{Study design}

All volunteers were free-living during the course of the study. Fe intake was measured by duplicate diet collection. Menstrual $\mathrm{Fe}$ losses were determined by the direct measurement of menstrual blood loss for one menstrual cycle. Fe status was measured in fasting blood samples taken on three consecutive mornings.

\section{Habitual intakes}

The habitual dietary Fe intake of each volunteer was assessed from a 7 d duplicate diet collection (West \& van Staveren, 1991). Volunteers were instructed to select meals that typified their normal dietary patterns for 1 week and to collect an exact duplicate of all food and drink consumed in each $24 \mathrm{~h}$ period into separate plastic containers. The daily duplicate diets were homogenised using a Janke and Kunkel IKA-Labortechnic Ultra-Turrax T-50 homogeniser (ESSLAB, Hadleigh, Essex, UK) and subsampled into acidwashed plastic vials. Subsamples were analysed for total Fe content by inductively coupled plasma MS. A $7 \mathrm{~d}$ household measures diary was also kept to confirm that subjects had been allocated to the appropriate dietary group, but these records were not used to estimate habitual dietary intakes.

\section{Preparation of duplicate diet samples for iron analysis}

An aliquot of sample ( $2 \mathrm{~g}$ wet weight), followed by concentrated nitric acid $(5 \mathrm{ml})$, was placed into a $50 \mathrm{ml}$ quartz reaction vessel. Groups of six vessels were heated in a Perkin Elmer Multiwave microwave digestion system (Perkin Elmer Ltd, Beaconsfield, Bucks., UK), following the manufacturer's operating conditions. When cool, the digests were transferred to graduated polystyrene test tubes and made up to volume $(10 \mathrm{ml})$ with deionised water. After thorough mixing, the digest liquor was further diluted, an 
internal standard was added, and the resulting solution was measured by inductively coupled plasma MS. Analytical batches included certified reference materials - NIST 1547 (peach leaves), NIST 1548a (typical diet) and NIST 8436 (durum wheat flour) (National Institute of Standards and Technology, Gaithersburg, MD, USA) - reagent blanks and a spiked reagent blank for recovery estimation purposes.

\section{Assessment of menstrual blood loss}

Subjects were supplied with sanitary protection: Tampax tampons (mini, regular, super, superplus; Proctor and Gamble, Newcastleupon-Tyne, UK) and Always towels (normal, normal plus, long plus, maxi night-time extra; Proctor and Gamble) and were asked to collect tampons and towels separately into plastic bags for the duration of one menstrual period. Volunteers used double-protection, i.e. towels and tampons simultaneously during the collection period, and were asked to report any blood losses that were not collected during the period. In order to minimise blood loss, tampons were changed before micturition or defecation. A $5 \mathrm{ml}$ venous blood sample was taken on day 2 or 3 of the menstrual period and used to standardise the assessment of menstrual blood loss. Each subject also completed a questionnaire concerning reproductive history and menstrual cycle to ensure that there was no regular bleeding between menstrual periods. The volunteers recorded the dates of consecutive menstrual periods in order to calculate average cycle length.

Menstrual blood loss was quantified using the alkaline haematin method (Hallberg \& Nilsson, 1964a) modified by Newton et al. (1977). Menstrual Fe loss was then calculated from the total menstrual blood loss of each volunteer using the following equation:

$$
\frac{\operatorname{MIL}(\mathrm{mg} / \mathrm{d})=\operatorname{MBL}(\mathrm{ml}) \times \mathrm{Hb}(\mathrm{mg} / \mathrm{ml}) \times 0.00334}{\text { Cycle length }}
$$

where MIL is menstrual Fe loss, MBL is menstrual blood loss, and 0.00334 is equivalent to the fraction of $\mathrm{Fe}$ in $\mathrm{Hb}$ at a concentration of $1 \mathrm{mg} / \mathrm{ml}$.

\section{Iron status}

On three consecutive days, following a $10 \mathrm{~h}$ overnight fast, a $25 \mathrm{ml}$ venous blood sample was removed from the antecubital vein of each volunteer. Serum ferritin concentration was used to assess Fe status and was determined in triplicate using an in-house ELISA (interassay CV $15 \%$ ) based on the method of Flowers et al. (1986). Batch analysis of each dietary group took place at the end of the study. C-reactive protein level was measured using an immunoturbidometric assay (Dako Ltd., Ely, Cambridgeshire, UK) at the Chemical Pathology Department at the Norfolk and Norwich University Hospital to ensure that the ferritin concentrations were not raised because of an inflammatory response or infection. Ferritin values were excluded if the C-reactive protein concentration was $>10 \mathrm{mg} / \mathrm{l}$. Transferrin saturation (interassay CV 9.1\%) was calculated from direct measurements of serum Fe concentration and total Fe-binding capacity using the equation:

$$
\% \text { Transferrin saturation }=(\text { serum Fe } / \text { TIBC }) \times 100
$$

where TIBC is total Fe-binding capacity.

The total serum $\mathrm{Fe}$ assay (interassay $\mathrm{CV} 5.5 \%$ ) was based on the method of Carter (1971). Total Fe-binding capacity (interassay CV 6.4\%) was calculated from the sum of measured unsaturated Fe-binding capacity and serum Fe. The unsaturated Fe-binding capacity assay involved the addition of a known amount of Fe to the plasma samples and the subsequent measurement of non-transferrin-bound Fe (Carter, 1971). Both methods were automated (Cobas Mira autoanalyser; Roche Diagnostics, Welwyn Garden City, Hertfordshire, UK) and Lyphochek assayed chemistry control (human; Bio-Rad, Hemel Hempstead, Hertfordshire, UK) was used for quality control. Samples were randomly analysed as all transferrin saturation assays were performed within $48 \mathrm{~h}$ of sample collection. Serum transferrin receptors were quantified in duplicate using a commercially available ELISA kit (interassay CV 5.8\%) (Quantikine IVD soluble transferrin receptor ELISA; R \& D Systems Inc., Minneapolis, MN, USA). Haematological parameters, including $\mathrm{Hb}$ and mean corpuscular volume, were measured using an MD8 Coulter Counter (Beckman Coulter, Fullerton, CA, USA). Assay precisions were calculated on a monthly basis as part of an external quality assurance programme (interassay $\mathrm{CV}<1 \%$ and $<4 \%$ for mean corpuscular volume and $\mathrm{Hb}$ respectively).

\section{Statistical analysis}

Statistical analysis was performed using the statistical package $\mathrm{R}$ (R Development Core Team, 2003). All data are presented as means and standard deviations, or median values and interquartile ranges if the data were skewed. The normality of all data was checked using the Shapiro-Wilk test. Evidence for a difference between habitual dietary $\mathrm{Fe}$ intake, Fe status measurements and subject characteristics in the three groups was tested using ANOVA. For non-normally distributed data, the KruskalWallis test was performed to test for differences in group location between the dietary groups. Evidence for a difference in contraceptive use in the three groups was tested using the $\chi^{2}$ test for independence, and a $P$-value was obtained by running 100000 Monte Carlo simulations.

The relationship between Fe stores (serum ferritin) and dietary $\mathrm{Fe}$ intake, menstrual $\mathrm{Fe}$ loss and dietary group was examined using a linear regression model, otherwise referred to as univariate ANOVA. Once the model had been trimmed of all non-significant terms, Tukey's honest significant difference test was used to identify differences between groups. Model assumptions (e.g. normality) were checked, but there was no need either to omit or to transform any data. In the final model, the remaining significant explanatory variables were complete, and data from all ninety volunteers were used. A significance level of $P<0.05$ was used for all statistical tests.

\section{Results}

All ninety subjects completed the study, and, unless otherwise stated, data are reported for thirty per group for each parameter measured. Missing data resulted from either technical difficulties with sample analysis or failure of the volunteer to provide an appropriate sample. In the final $\mathrm{Fe}$-status model, data from eighty-six volunteers were used as ferritin data were excluded for four subjects owing to a raised C-reactive protein level.

\section{Subject characterisation and menstrual blood loss}

Table 1 summarises the subject characteristics and menstrual blood loss data for each dietary group. The three groups were well matched: no significant difference was found between the 
Table 1. Subject characteristics, menstrual blood loss (MBL) per cycle and daily loss of iron from menses (MIL)

(Mean and standard deviation, or median and interquartile range)

\begin{tabular}{|c|c|c|c|c|c|c|}
\hline & \multicolumn{2}{|c|}{ Red meat } & \multicolumn{2}{|c|}{ Poultry/fish } & \multicolumn{2}{|c|}{ Lacto-ovo-vegetarian } \\
\hline & Mean & SD & Mean & SD & Mean & SD \\
\hline Age (years) & 34 & 6 & 32 & 7 & 31 & 6 \\
\hline Height (m) & 1.66 & 0.07 & 1.65 & 0.06 & 1.66 & 0.06 \\
\hline Weight (kg) & $66 \cdot 2$ & $10 \cdot 0$ & 66.4 & $11 \cdot 0$ & $64 \cdot 8$ & $13 \cdot 2$ \\
\hline $\mathrm{BMI}\left(\mathrm{kg} / \mathrm{m}^{2}\right)$ & 24 & 3 & 24 & 4 & 23 & 4 \\
\hline MBL/cycle (ml) & $25 \cdot 1$ & $8 \cdot 5,45 \cdot 8^{\dagger}$ & $15.2^{*}$ & $(8 \cdot 2,31 \cdot 3)^{\dagger}$ & $15 \cdot 6^{*}$ & $9 \cdot 0,22 \cdot 1^{\dagger}$ \\
\hline Length of cycle (d) & 28 & 2 & 28 & 5 & 29 & 4 \\
\hline $\mathrm{MIL}(\mathrm{mg} / \mathrm{d})$ & 0.40 & $0.14,0.71^{\dagger}$ & $0.25^{\star}$ & $(0.13,0.52)^{\dagger}$ & $0.23^{\star}$ & $0.13,0.35^{\dagger}$ \\
\hline \multicolumn{7}{|c|}{ Method of contraception (\%) } \\
\hline Oral contraceptives & \multicolumn{2}{|c|}{30} & \multicolumn{2}{|c|}{40} & \multicolumn{2}{|c|}{37} \\
\hline Intrauterine device & \multicolumn{2}{|c|}{10} & \multicolumn{2}{|c|}{0} & \multicolumn{2}{|c|}{6} \\
\hline Other & \multicolumn{2}{|c|}{60} & \multicolumn{2}{|c|}{60} & \multicolumn{2}{|c|}{57} \\
\hline
\end{tabular}

*Median.

†Interquartile range

groups for height, weight, BMI, contraceptive use or age. Owing to the fact that the menstrual blood loss data were skewed, median values are presented.

Statistical analysis of the data demonstrated no significant difference in menstrual blood loss between the groups $(P=0 \cdot 399)$. The menstrual blood loss followed an exponential distribution (Fig. 1); the median menstrual blood loss for all groups was $17.6 \mathrm{ml}$, with a mean cycle length of 28 (SD 4) d. Similarly, menstrual $\mathrm{Fe}$ losses were not significantly different between the dietary groups and, when averaged over a menstrual cycle, the mean loss of the combined data for all groups was 0.43 (SD 0.45 ) $\mathrm{mg} / \mathrm{d}$ (overall median value $0.26 \mathrm{mg} / \mathrm{d}$ ), and $70 \%$ of the women lost less than $0.5 \mathrm{mg} \mathrm{Fe} / \mathrm{d}$ through menses. The method of contraception used by the subjects is also given in Table 1. A total of $35.5 \%$ of all volunteers used oral contraceptives, whereas only $5.5 \%$ of all subjects used an intrauterine device. There was a significantly lower $(P<0.001)$ median blood loss $(\mathrm{ml} /$ cycle $)$ in oral contraceptive users than in those using other forms of contraception (excluding intrauterine devices) (oral contraceptives 10.0 v. 32.9 ; oral contraceptives 11.6 v. 17.69; oral contraceptive 13.0 $v .18 .0$ in the red meat, poultry/fish and vegetarian groups, respectively). There were too few users of intrauterine devices to draw any meaningful conclusions from the data.

\section{Dietary intake}

There was a significant difference in habitual dietary Fe intake between the three groups $(P=0 \cdot 025)$. The red meat group had a

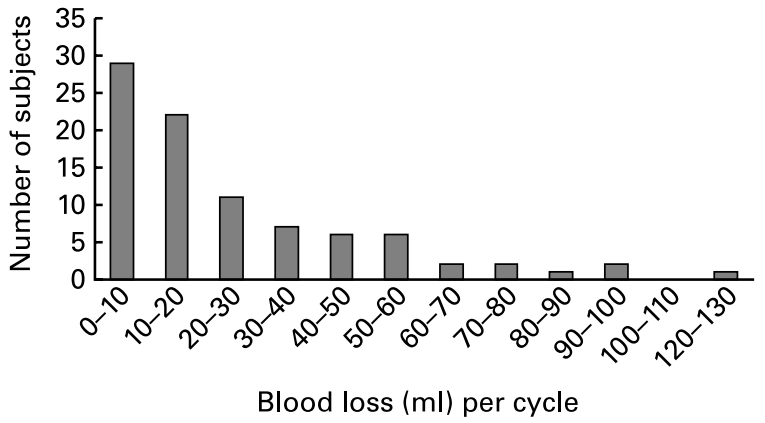

Fig. 1. Frequency distribution of menstrual blood loss ( $\mathrm{ml} / \mathrm{cycle})$ in women aged $18-45$ years $(n 90)$. significantly lower mean intake than the lacto-ovo-vegetarian group: 10.9 (SD 4.3) and 14.5 (SD 5.5) $\mathrm{mg} / \mathrm{d}$, respectively. The poultry/fish group had an intermediate intake of $12 \cdot 8$ (SD $5 \cdot 1) \mathrm{mg} / \mathrm{d}$, which was not significantly different from that of the other two groups.

\section{Iron status}

Data for the various measures of Fe status are given in Table 2. The mean $\mathrm{Hb}$ concentration for each group was within the normal range and was not significantly different between the groups. The serum ferritin data were normally distributed after taking the effects of menstrual Fe loss and dietary group into consideration. The median serum ferritin concentration was significantly lower in the red meat group than in the poultry/fish group $(P<0 \cdot 01)$. This was consistent with the observation that the red meat group had a significantly lower Fe intake. The median serum ferritin for the vegetarian group was not significantly different from that of the other two groups. The mean transferrin receptor concentration also differed between groups $(P=0.002)$, with a significantly higher concentration in the lacto-ovo-vegetarian group than in the poultry/fish and red meat groups. This suggested a higher degree of $\mathrm{Fe}$ depletion in the lacto-ovo-vegetarian group; however, the serum ferritin concentration was not significantly different. All other parameters lay within the normal range, and there were no significant differences between dietary groups.

\section{Factors affecting iron status}

The linear regression model (ANOVA) used to investigate the relationship between Fe status (serum ferritin) and a range of biologically relevant variables indicated that menstrual $\mathrm{Fe}$ loss $(P<0.001)$ and dietary group $(P=0.040)$ were important predictors of $\mathrm{Fe}$ status, but total $\mathrm{Fe}$ intake was not related to $\mathrm{Fe}$ status. Menstrual $\mathrm{Fe}$ loss was negatively correlated with serum ferritin, indicating that a high blood loss was associated with low Fe stores. The model also suggested that the poultry/fish group had a significantly higher $\mathrm{Fe}$ status than the red meat group, but no other dietary interaction was significant. Menstrual Fe loss and dietary group contributed $11.5 \%$ and $6.7 \%$, respectively, to the total sum of the squared deviance for Fe status. 
Table 2. Measures of iron status ( $n 30$ unless otherwise stated)

(Mean and standard deviation, or median and interquartile range)

\begin{tabular}{|c|c|c|c|c|c|c|}
\hline & \multicolumn{2}{|c|}{ Red meat } & \multicolumn{2}{|c|}{ Poultry/fish } & \multicolumn{2}{|c|}{ Vegetarian } \\
\hline & Mean & SD & Mean & SD & Mean & SD \\
\hline $\mathrm{Hb}(\mathrm{g} / \mathrm{l})$ & 134 & 7 & 137 & 11 & 135 & 7 \\
\hline Serum ferritin $(\mu \mathrm{g} / \mathrm{l})$ & $6 \cdot 8^{\star} \ddagger$ & $3 \cdot 3,16 \cdot 3 \dagger(n 28)$ & $17 \cdot 5^{\star}$ & $11 \cdot 3,22 \cdot 4 \dagger(n 29)$ & $11 \cdot 1^{*}$ & $6 \cdot 4,20 \cdot 4 \dagger(n 29)$ \\
\hline Transferrin receptor (mg/l) & 3.19 & $2.04 \dagger$ & 2.63 & $1 \cdot 18^{\S}$ & 3.92 & 1.35 \\
\hline Transferrin saturation (\%) & 21 & 9 & 27 & 13 & 22 & 8 \\
\hline Serum Fe $(\mu \mathrm{g} / \mathrm{l})$ & 801 & $289(n 27)$ & 901 & $308(n 26)$ & 855 & $346(n 24)$ \\
\hline Total Fe binding capacity $(\mu \mathrm{g} / \mathrm{l})$ & 391 & $61(n 27)$ & 381 & $60(n 26)$ & 387 & $44(n 24)$ \\
\hline Mean cell volume $(\mathrm{fl})$ & 88.5 & 4.5 & $88 \cdot 8$ & $4 \cdot 3$ & $89 \cdot 0$ & 2.9 \\
\hline
\end{tabular}

*Median.

†Interquartile range.

ISignificantly lower than poultry/fish group $(P<0.01)$

$\S$ Significantly lower than the lacto-ovo-vegetarian group $(P=0.002)$.

The linear regression models were repeated using transferrin saturation and transferrin receptors as response variables. In the case of transferrin saturation, menstrual $\mathrm{Fe}$ loss was the only significant explanatory variable $(P<0.001)$, with an increase in menstrual $\mathrm{Fe}$ loss resulting in a decrease in transferrin saturation. Dietary group $(P=0 \cdot 002)$ was the only significant variable when transferrin receptor concentration was used as the response variable, the lacto-ovo-vegetarian group having significantly higher concentrations of transferrin receptors than both the red meat and poultry/fish groups.

\section{Discussion}

It has been suggested that Fe nutrition in vegetarians may not be optimal: (a) because haem $\mathrm{Fe}$ is more readily absorbed than nonhaem Fe; (b) because meat enhances non-haem Fe absorption via the as-yet-unidentified 'meat factor'; (c) because vegetarian diets generally contain higher quantities of inhibitors of $\mathrm{Fe}$ absorption, for example, phytate, tannins and Ca (Hallberg \& Hulthen, 2000). Although haem Fe represents only $10-15 \%$ of dietary Fe intake in meat-eaters, it could contribute at least $40 \%$ of the total $\mathrm{Fe}$ absorbed. Estimating the haem Fe content of diets is somewhat problematic owing to the technical difficulties associated with direct measurement of the haem Fe content of flesh foods. It is, however, generally reported that red meat (beef, lamb, pork) contains approximately $60 \%$ haem Fe (Rangan et al. 1997b; Purchas et al. 2003), poultry in the region of $20-40 \%$ (Hendricks et al. 1987; Han et al. 1993), and fish 18-75\% (Rangan et al. 1997b; Gomez-Basauri \& Regenstein, 1992).

Vegetarians have been reported to have lower Fe stores (McEndree et al. 1983; Faber et al. 1986; Worthington-Roberts et al. 1988) despite an adequate Fe intake (Helman \& DarntonHill, 1987; Reddy \& Sanders, 1990; Alexander et al. 1994). In some investigations, the prevalence of Fe-deficiency anaemia (determined by $\mathrm{Hb}$ concentration) is similar to that of omnivores (Nelson et al. 1994), whereas other studies report lower $\mathrm{Hb}$ concentrations in vegetarians (Nathan et al. 1996). Longterm lacto-ovo-vegetarians and female vegans, even with a high dietary fibre (and hence phytate) intake, have been found to have a similar Fe status to omnivores (Craig, 1994; Haddad et al. 1999), supporting the hypothesis that homeostasis is maintained through an upregulation of $\mathrm{Fe}$ absorption. It appears, however, that adaptation can only occur with a high-bioavailability diet (Hunt, 2003), which illustrates the key role played by the diet in determining Fe balance.
It is difficult to detect mild $\mathrm{Fe}$ deficiency because of the absence of a definitive biomarker of Fe status. Serum ferritin concentration is a sensitive, but not necessarily specific, measure of Fe stores: phlebotomy studies have established that a concentration of $1 \mu \mathrm{g} / \mathrm{l}$ corresponds to mobilisable Fe stores of about $8 \mathrm{mg}$ (Walters et al. 1973). However, the cut-off value that indicates a depletion of $\mathrm{Fe}$ stores is subject to debate, with recommended values ranging from 10 to $15 \mu \mathrm{g} / \mathrm{l}$ (Australian Iron Status Advisory Panel, 1996; Milman et al. 1998) up to $22 \mu \mathrm{g} / \mathrm{l}$ (Suominen et al. 1998). Ferritin is an acute-phase protein so its level is raised in periods of acute inflammation or infection, and it can remain elevated for weeks after the infection has disappeared (Hulthen et al. 1998).

It is clear from the data in the present study (Fig. 2) that a substantial proportion of women in all three dietary groups had low or absent Fe stores, but the serum ferritin distribution of the poultry/fish group was different from that of the other two groups and indicated a lesser degree of Fe deficiency: $60 \%$ of the red meat group, $40 \%$ of the vegetarians and $20 \%$ of the poultry/fish group had a serum ferritin concentration $<10 \mu \mathrm{g} / \mathrm{l}$. As no women volunteering for the study were excluded because of anaemia, the potential bias in Fe status between the groups was minimised. There was no other haematological evidence to suggest that these individuals had progressed beyond the first phase of Fe deficiency (stage I), resulting in Fe-deficient erythropoiesis

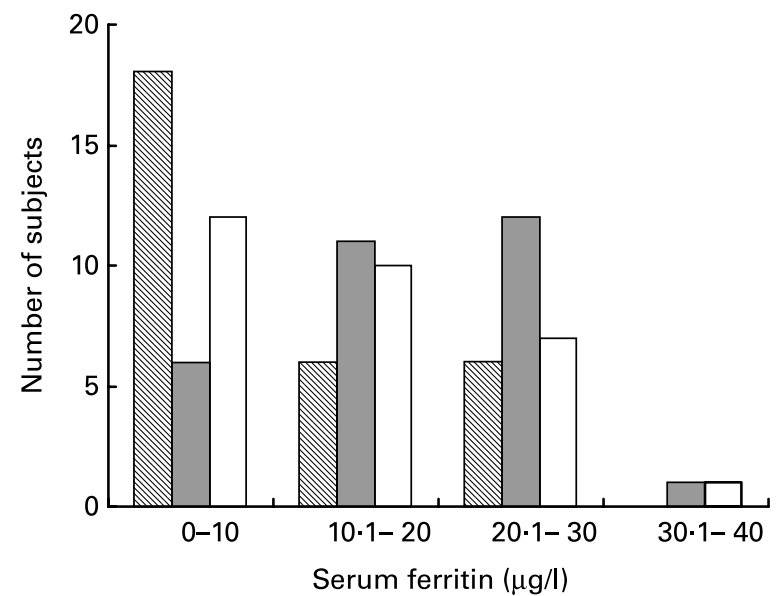

Fig. 2. Distribution of serum ferritin $(\mu \mathrm{g} / \mathrm{l}) \mathbb{\mathbb { Q }}$, Red meat; $[$, poultry/fish; $\square$, lacto-ovo-vegetarian. 
(stage II) (Suominen et al. 1998). Fe-deficiency anaemia (stage III), diagnosed as an $\mathrm{Hb}$ value $<120 \mathrm{~g} / \mathrm{l}$ (World Health Organization, 1994), was not observed in any of the groups. The lacto-ovo-vegetarian group had a significantly higher transferrin receptor concentration than the poultry/fish group, which suggests that they were slightly more Fe-deficient. Although not statistically significant, the poultry/fish group appeared to have the highest Fe status, with the highest ferritin, transferrin saturation, serum $\mathrm{Fe}$ and $\mathrm{Hb}$ concentrations of all three groups, as well as the lowest transferrin receptor concentration.

Menstrual $\mathrm{Fe}$ loss was the key factor in the determination of $\mathrm{Fe}$ status in this study, accounting for $11.5 \%$ of the variance in ferritin concentration. Menstrual blood loss in individuals varies little between cycles (Hallberg \& Nilsson, 1964b), but intra-individual variation is considerable (Hallberg et al. 1966). Studies in identical and non-identical twins have established that menstrual blood losses are largely under genetic control (Rybo \& Hallberg, 1966). A comprehensive study carried out in Sweden in the mid1960s (Hallberg et al. 1966) found the mean blood loss per menstrual cycle was $44 \mathrm{ml}$, which equates to an average $\mathrm{Fe}$ loss of $0.7 \mathrm{mg} / \mathrm{d}$. The Swedish data were, however, collected before the widespread use of oral contraceptives, which are known to reduce blood loss (Larsson et al. 1992). In this earlier study, it was reported that only one subject was using oral contraceptives, whereas latest figures in the UK suggest that almost one-third $(32 \%)$ of women use some form of oral contraceptive (Lawrenson et al. 1999). Intrauterine devices also alter menstrual blood loss, but in the opposite direction (Milsom et al. 1995), and it is reported that only $2.2 \%$ of women prefer to use this method of contraception (Lawrenson et al. 1999). In the present study, the mean blood loss was $26 \mathrm{ml} /$ cycle, which could be explained by the use of oral contraceptives in approximately $30 \%$ of the women, but in addition, the nature of the study meant that the volunteers were a self-selected group, possibly with a non-representative number of women with high menstrual losses.

Previous studies investigating the effect of menstrual blood loss on Fe status have mainly used qualitative estimates of menstrual blood loss. The advantage of the present study was that direct measurements were made, which enabled us to quantify menstrual $\mathrm{Fe}$ loss. Most of the earlier studies used surrogate estimates of menstrual blood loss such as self-reported duration (Razagui et al. 1991), frequency of menstruation (Worthington-Roberts et al. 1988) or pre- or postmenopausal status (i.e. menstrual blood loss or no menstrual blood loss; Kenney, 1985; Bairati et al. 1989; Yokoi et al. 1994). The results are inconsistent: one study found no association between self-reported estimated blood loss and serum ferritin level (Bairati et al. 1989), whereas another found a positive correlation (Kenney, 1985). It is widely accepted that women's ability to self-report menstrual blood loss is highly inaccurate (Hallberg et al. 1966) so conclusions from qualitative studies should be viewed with caution.

Several studies have shown that serum ferritin is related to the length of the menstrual period (Galan et al. 1985; Soustre et al. 1986; Milman et al. 1993; Rangan et al. 1997a), and in a recent study on the aetiology of mild Fe deficiency in premenopausal New Zealand women, it was observed that serum ferritin level correlated with the duration of menstruation and extent of bleeding (Heath et al. 2001) assessed from a menstrual recall method (Heath et al. 1998). In response to the correlation between serum ferritin and menstrual blood loss, the Institute of Medicine's Dietary Reference Intakes report on micronutrients (Food and Nutrition Board/Institute of Medicine, 2000) used menstrual blood loss as the basis for setting the RDA for $\mathrm{Fe}$ in women of childbearing age.

The results of the present study demonstrated that menstrual $\mathrm{Fe}$ loss was inversely related to $\mathrm{Fe}$ status (ferritin), with higher menstrual Fe losses resulting in a lower Fe status $(P<0.001)$; on average, a $1 \mathrm{mg} / \mathrm{d}$ increase in menstrual $\mathrm{Fe}$ loss resulted in a decrease in serum ferritin of $6.9 \mu \mathrm{g} / \mathrm{l}$. The data in this study were obtained from direct measurements of menstrual blood loss using the 'gold standard' alkaline haematin method, but this is not appropriate for widespread diagnostic use. A simple menstrual pictogram has been developed and validated, and can be used to provide a semi-quantitative estimate of menstrual blood loss and to diagnose heavy menstrual bleeding (Wyatt et al. 2001).

Total dietary Fe intake was shown to be unrelated to Fe stores, but dietary group was a key determinant of Fe status, accounting for $6.7 \%$ of the variance in serum ferritin concentration. A detailed investigation of the active dietary components was not possible in the present study, although additional dietary analysis is currently underway to attempt to identify which dietary factors are most important. Liu et al. (2003) studied the relationship between diet and body $\mathrm{Fe}$ stores in postmenopausal women and found a significant $(P<0.01)$ correlation (Spearman partial correlation coefficient) between plasma ferritin and haem Fe intake $(r$ 0.15), red meat intake $(r \quad 0 \cdot 11)$, Fe supplementation $(r$ 0.12) and alcohol $(r 0.14)$, and a negative correlation $(P<0.05)$ with phytate $(r-0.09)$. The group had a higher Fe status (median serum ferritin $73.8 \mu \mathrm{g} / \mathrm{l}$ ) than the premenopausal women in the present study (median serum ferritin for all groups $13.0 \mu \mathrm{g} / \mathrm{l}$ ) but similar Fe intakes (median $10 \cdot 2 \mathrm{mg} / \mathrm{d}$ ). Fe intake was assessed by a food-frequency questionnaire, which is less accurate than our $7 \mathrm{~d}$ duplicate-diet method, which gave a median $\mathrm{Fe}$ intake of $11.9 \mathrm{mg} / \mathrm{d}$.

The results of this study indicate that a large proportion of UK women of childbearing age may be in a precarious position with regard to the supply of Fe from the diet. A high number are at risk of becoming Fe deficient, and the data suggest that those habitually consuming a diet containing poultry and fish may have a higher Fe status than red meat consumers, whereas a lacto-ovovegetarian diet does not confer any additional risk or benefit. Although the red meat group had a significantly lower serum ferritin level than the poultry/fish group, their habitual Fe intake $(10.9 \mathrm{mg} / \mathrm{d})$ was, however, significantly lower than that of the lacto-ovo-vegetarian group $(14.5 \mathrm{mg} / \mathrm{d})$ and not dissimilar to the mean $\mathrm{Fe}$ intake from food in women aged 19-49 years $(9.4 \mathrm{mg} /$ d) in the second adult National Diet and Nutrition Survey (Henderson et al. 2003). It should be pointed out that the latter figure is derived from food diaries and a food composition database, whereas our data were generated by analysing a $7 \mathrm{~d}$ duplicate diet. The latter, more accurate, technique is required for evaluating relationships between nutrient intake and other factors on an individual basis. The mean ferritin concentration indicated that all groups had low Fe stores. There was no significant difference between the dietary groups for any other indicator related to $\mathrm{Fe}$ status, apart from a significantly raised transferrin receptor concentration in the vegetarian group compared with the poultry/fish group.

In summary, menstrual blood loss was the most significant factor affecting Fe status, and, although less important, the type of diet consumed by the women had a significant effect on serum ferritin concentration. The women of childbearing age who volunteered 
for our study had low Fe stores, but the consumption of a lacto-ovovegetarian diet was not associated with a lower Fe status compared with omnivorous diets. The Fe stores of the women who ate poultry and fish were significantly higher than those of the women who ate red meat. Further investigations need to be carried out to determine what factors within the three types of diet are responsible for the differences in Fe status. Since menstrual Fe loss is a key determinant of $\mathrm{Fe}$ status, strategies to prevent Fe deficiency in women should include an assessment of menstrual blood loss. Those with a high menstrual blood loss may be able to decrease their risk of $\mathrm{Fe}$ deficiency by using oral contraceptives, which are reported to decrease blood loss by approximately $50 \%$ (Callard et al. 1966).

\section{Acknowledgements}

The authors would like to thank all the volunteers who took part in the study, Brie Wharf, Cate Macrow, Angie Twaite and the Human Nutrition Unit staff for their invaluable assistance with the human study, and the Food Standards Agency and the Biological and Biotechnological Sciences Research Council for funding the work.

\section{References}

Alexander D, Ball MJ \& Mann J (1994) Nutrient intake and haematological status of vegetarians and age-sex matched omnivores. Eur J Clin Nutr 48, 538-546.

Anderson JW, Konz EC \& Jenkins DJA (2000) Health advantages and disadvantages of weight-reducing diets: a computer analysis and critical review. J Am Coll Nutr 19, 578-590.

Andrews NC (1999) Disorders of iron metabolism. N Engl J Med 341, 1986-1995.

Australian Iron Status Advisory Panel (1996) Iron Deficiency in Adults: A Comprehensive Management Guide. Sydney: Australian Iron Status Advisory Panel.

Bairati I, Herbeth B, Spyckerelle, Didelotbarthelemy J, Galan P, Hercberg S, Christides JP \& Decourcy GP (1989) Dietary intake and other determinants of iron and folate status in female adolescents. J Clin Biochem Nutr 7, 143-151.

Ball MJ \& Bartlett MA (1999) Dietary intake and iron status of Australian vegetarian women. Am J Clin Nutr 70, 353-358.

Barr SI (1999) Vegetarianism and menstrual cycle disturbances: is there an association? Am J Clin Nutr 70, 549S-554S.

Bjorn-Rasmussen E, Hallberg L, Isaksson B \& Arridson B (1974) Food iron absorption in man. J Clin Invest 53, 247-255.

Borch-Iohnsen B, Meltzer HM, Stenberg V \& Reinskou T (1990) Iron status in a group of Norwegian menstruating women. Eur J Clin Nutr 44, 23-28.

Borel MJ, Smith SM, Derr J \& Beard JL (1991) Day-to-day variation in iron-status indices in healthy men and women. Am J Clin Nutr $\mathbf{5 4}$, 729-735.

Bothwell TH, Charlton RW, Cook JD \& Finch CA (1979) Iron Metabolism in Man. London: Blackwell Scientific

Callard GV, Litovsky FS \& DeMerre LJ (1966) Menstruation in women with normally or artificially controlled cycles. Fert Steril 17, 684-688.

Carter P (1971) Spectrophotometric determination of serum iron at the submicrogram level with a new reagent (ferrozine). Anal Biochem 40, $450-458$

Cooper MJ \& Zlotkin SH (1996) Day-to-day variation of transferrin receptor and ferritin in healthy men and women. Am J Clin Nutr 64, $738-742$.

Craig WJ (1994) Iron status in vegetarians. Am J Clin Nutr 59, 1233S-1237S

Department of Health (1991) Reference values for food, energy and nutrients for the United Kingdom. In Report of the Panel on Dietary Refer- ence Values of the Committee on Medical Aspects of Food Policy. London: HMO.

Faber M, Gouws E, Benade AJ \& Labadarios D (1986) Anthropometric measurements, dietary intake and biochemical data of South African lacto-ovo vegetarians. S Afr Med J 69, 733-738.

Food and Agriculture Organization/World Health Organization (1988) Requirements of Vitamin A, Iron, Folate and Vitamin B12. Report of a Joint FAO/WHO Expert Consultation. FAO Food and Nutrition Series no. 23. Rome: FAO.

Flowers CA, Kuizon M, Beard JL, Skikne BS, Covell AM \& Cook JD (1986) A serum ferritin assay for prevalence studies of iron deficiency. Am J Hematol 23, 141-151.

Food and Nutrition Board/Institute of Medicine (2000) Dietary Reference Intakes for Vitamin A, Vitamin K, Arsenic, Boron, Chromium, Copper, Iodine, Iron, Manganese, Molybdenum, Nickel, Silicon, Vanadium and Zinc. A Report of the Panel on Micronutrients, Subcommittees on Upper Reference Levels of Nutrients and of Interpretation and Uses of Dietary Reference Intakes, and the Standing Committee on the Scientific Evaluation of Dietary Reference Intakes. Washington, DC: National Academy Press.

Galan S, Hercberg S, Soustr Y, Dop MC \& Dupin H (1985) Factors affecting iron stores of French female students. Hum Nutr Clin Nutr 39C, 279-287.

Gomez-Basauri JV \& Regenstein JM (1992) Processing and frozen storage effects on the iron content of cod and mackerel. J Food Sci 57, $1332-1336$

Haddad EH, Berk LS, Kettering JD, Hubbard RW \& Peters WR (1999) Dietary intake and biochemical, hematologic and immune status of vegans compared with non-vegetarians. Am $J$ Clin Nutr $\mathbf{7 0}$, $586 \mathrm{~S}-593 \mathrm{~S}$.

Hallberg L (1995) Results of surveys to assess iron status in Europe. Nutr Rev 53, 314-322.

Hallberg L, Hogdahl A-M, Nilsson L \& Rybo G (1966) Menstrual blood loss - a population study. Variations at different ages and attempts to define normality. Acta Obstet Gynecol Scand 45, 320-351.

Hallberg L \& Hulthen L (2000) Prediction of dietary iron absorption: an algorithm for calculating absorption and bioavailability of dietary iron. Am J Clin Nutr 71, 1147-1160.

Hallberg L \& Nilsson L (1964a) Determination of menstrual blood loss. Scand J Clin Lab Invest 16, 244-248.

Hallberg L \& Nilsson L (1964b) Constancy of individual menstrual blood loss. Acta Obstet Gynecol Scand 43, 352-359.

Han D, McMillin KW, Godber JS, Bidner TD, Younathan MT, Marshall DL \& Hart LT (1993) Iron distribution in heated beef and chicken muscles. J Food Sci 58, 697-700.

Heath A-LM, Skeaff CM \& Gibson R (1998) Validation of a questionnaire method for estimating extent of menstrual blood loss in young adult women. J Trace Elem Med Biol 12, 231-235.

Heath A-LM, Skeaff CM, Williams S \& Gibson R (2001) The role of blood loss and diet in the aetiology of mild iron deficiency in premenopausal adult New Zealand women. Pub Health Nutr 4, 197-206.

Helman AD \& Darnton-Hill I (1987) Vitamin and iron status in new vegetarians. Am J Clin Nutr 45, 785-789.

Henderson L, Gregory J \& Swan G (2002) The National Diet and Nutrition Survey: Adults Aged 19 to 64 Years, vol. 1. London: HMSO.

Henderson L, Irving K, Gregory J, Bates CJ, Prentice A, Perks J, Swan G \& Farron M (2003) The National Diet and Nutrition Survey: Adults Aged 19 to 64 Years, vol. 1. London: HMSO.

Hendricks DG, Mahoney AW, Zhang D \& Yu Y (1987) Validity and assumptions in estimating heme iron for determining available dietary iron. Fed Proc 46, 1160.

Higham JM \& Shaw RW (1999) Clinical associations with objective menstrual blood volume. Eur J Obstet Gynecol 82, 73-76.

Hulthen L, Lindstedt G, Lundberg P-A \& Hallberg L (1998) Effect of mild infection on serum ferritin concentration - clinical and epidemiological implications. Eur J Clin Nutr 52, 76-79. 
Hunt JR (2003) High-, but not low-bioavailability diets enable substantial control of women's iron absorption in relation to body iron stores, with minimal adaptation within several weeks. Am J Clin Nutr 78, $1168-1177$.

Kenney MA (1985) Factors related to iron nutrition of adolescent females. Nutr Res 5, 157-166.

Larsson G, Milsom I, Lindstedt G \& Rybo G (1992) The influence of a low-dose combined oral contraceptive on menstrual blood loss and iron status. Contraception 46, 327-334.

Lawrenson RA, Leydon GM, Williams TJ, Newson RB \& Feher MD (1999) Patterns of contraception in UK women with type 1 diabetes mellitus: a GP database study. Diabet Med 16, 395-399.

Liu J-M, Hankinson SE, Stampfer MJ, Rifai N, Willett WC \& Ma J (2003) Body iron stores and their determinants in healthy postmenopausal US women. Am J Clin Nutr 78, 1160-1167.

McEndree L, Kies C \& Fox H (1983) Iron intake and nutritional status of lacto-ovovegetarian and omnivore students eating in a lacto-ovo vegetarian food service. Nutr Rep Int 27, 199-206.

Milman N, Clausen J \& Byg K-E (1998) Iron status in 268 Danish women aged 18-30 years: influence of menstruation, contraceptive method, and iron supplementation. Ann Hematol 77, 13-19.

Milman N, Rosdahl N, Lyhne N, Jorgensen T \& Graudal N (1993) Iron status in Danish women aged 35-65 years: relation to menstruation and method of contraception. Act Obstet Gynecol Scand 72, 601-605.

Milsom I, Andersson K, Jonasson K, Lindstedt G \& Rybo G (1995) The influence of the Gyne-T 380S IUD on menstrual blood loss and iron status. Contraception 52, 175-179.

Morabia A, Bernstein MS, Heritier S \& Beer-Borst S (1999) A Swiss population based assessment of dietary habits before and after the March 1996 'mad cow disease' crisis. Eur J Clin Nutr 53, 158-163.

Nathan I, Hackett AF \& Kirby S (1996) The dietary intake of a group of vegetarian children aged 7-11 years compared with matched omnivores. Br J Nutr 75, 533-544.

Nelson M, Bakaliou F \& Trivedi A (1994) Iron-deficiency anaemia and physical performance in adolescent girls from different ethnic backgrounds. Br J Nutr 72, 427-433.

Newton J, Barnard G \& Collins W (1977) A rapid method for measuring menstrual blood loss using automatic extraction. Contraception 16, 269-282.

Purchas RW, Simcock DC, Knight TW \& Wilkinson BHP (2003) Variation in the form of iron in beef and lamb meat and losses of iron during cooking and storage. Int J Food Sci Technol 38, 827-837.

Rangan AM, Aitken I, Blight GD \& Binns CW (1997a) Factors affecting iron status in 15-30 year old female students. Asia Pacific J Clin Nutr 6, 291-295.
Rangan AM, Ho RWL, Blight GD \& Binns CW (1997b) Haem iron content of Australian meats and fish. Food Austr 49, 508-511.

Razagui IB, Barlow PJ, Izmeth MGA \& Taylor KDA (1991) Iron status in a group of long-stay mentally handicapped menstruating women: some dietary considerations. Eur J Clin Nutr 45, 331-340.

R Development Core Team (2003), R: A Language and Environment for Statistical Computing. http://www.R-project.org

Reddy S \& Sanders TA (1990) Hematological studies on pre-menopausal Indian and Caucasian vegetarians compared with Caucasian omnivores. Br J Nutr 64, 331-338.

Rybo G \& Hallberg L (1966) Influence of heredity and environment on normal menstrual blood loss. Acta Obstet Gynecol Scand 45, 389-410.

Soustre Y, Dop MC, Galan P \& Hercberg S (1986) Dietary determinants of iron status in menstruating women. Int $J$ Vitam Nutr Res 56, 281-286.

Suominen P, Punnonen K, Rajamaki A \& Irjala K (1998) Serum transferrin receptor and transferrin receptor-ferritin index identify healthy subjects with subclinical deficits. Blood 92, 2834-2839.

Vegetarian Society (2000) 21st Century Vegetarian through the Ages. http://www.vegsoc.org/news/2000/21 cv/ages.html

Vegetarian Society Summary of RealEat Polls 1984-2001. (2001) www.vegsoc.org/info/realeat.html

Walters GO, Miller FM \& Worwood M (1973) Serum ferritin concentration and iron stores in normal subjects. J Clin Pathol 26, 770-772.

West CE \& van Staveren WA (1991) Food composition, nutrient intake and the use of food composition tables. In Design Concepts in Nutritional Epidemiology, pp. 102-103 [BM Margetts and M Nelson, editors]. New York: Oxford University Press.

Whitfield JB, Treloar S, Zhu G, Powell LW \& Martin NG (2003) Relative importance of female specific and non-female specific effects on variation in iron stores between women. Br J Haematol 120, 860-866.

World Health Organization (1994) Indicators and Strategies for Iron Deficiency and Anemia Programmes. Report of the WHO/UNICEF/ UNU Consultation. Geneva: WHO.

Worthington-Roberts BS, Breskin MW \& Monsen ER (1988) Iron status of premenopausal women in a university community and its relationship to habitual dietary sources of protein. Am J Clin Nutr 47, 275-279.

Wyatt KM, Dimmock PW, Walker TJ \& O'Brien PMS (2001) Determination of total menstrual blood loss. Fertil Steril 76, 125-131.

Yokoi K, Alcock N \& Sandstead H (1994) Iron and zinc nutriture of premenopausal women; associations of diet with serum ferritin and plasma zinc disappearance, and of serum ferritin with plasma zinc and plasma disappearance. J Lab Clin Med 124, 852-131. 